\title{
A New Approach to the Registration of Buildings towards 3D Land and Property Management in Slovakia
}

\author{
Vladimír Raškovič ${ }^{1}$, Zlatica Muchová ${ }^{2, *}$ and František Petrovič ${ }^{3}$ \\ 1 Research Institute of Geodesy and Cartography of the Slovak Republic in Bratislava, \\ 82012 Bratislava, Slovakia \\ 2 Department of Landscape Planning and Land Consolidation, Slovak University of Agriculture in Nitra, \\ 94976 Nitra, Slovakia \\ 3 Department of Ecology and Environmental Sciences, Constantine the Philosopher University in Nitra, \\ 94974 Nitra, Slovakia \\ * Correspondence: zlatica.muchova@uniag.sk
}

Received: 30 July 2019; Accepted: 25 August 2019; Published: 27 August 2019

\begin{abstract}
Slovakia faces a critical period in land and property management. The Land Registry still maintains its old 1990s information system and obsolete manual record system, whose structure and links of the real estate records and ownership titles are unable to meet the current requirements of companies in its graphical representation and visualization of data. Basically, it is a partially structured, digitalized and yet still analog system for recording land titles. It is of the utmost importance for a data model to be set up for a new information system that would provide the entire Land Registry with a wide range of information, together with the right structuring, filtering, sorting, and graphics. The system architecture should be based on unique identifiers in Land Registry entries, fixed links and integrity control mechanisms, while creating an index map of all real estate which can be specified with additional information future legislation might require. Slovak law allows multiple ownership of any land, building or interior. In order to initiate the entire process, the Slovak Land Registry needs to clearly define buildings together with their boundaries by their geometry and location, identify them with a unique code and give them a fixed land reference.
\end{abstract}

Keywords: cadaster; building; construction; property; 3D real cadaster; Slovakia

\section{Introduction}

A cadaster is normally a parcel-based and up-to-date land information system containing a record of interests in the land (e.g., rights, encumbrances, and responsibilities). It usually includes a geometric description of the land plots linked to other records describing the nature of the interests and often the value of the parcel and improvements thereto. It may be established for fiscal (valuation and equitable taxation) or legal (conveyance) purposes, to assist in land management and use (for planning and other administrative purposes) and enables sustainable development and environmental protection [1]. Current cadastral data in models found in Slovakia use only a 2D land-parcel concept (see, e.g., [2]). However, the development of information systems has also brought new requirements to the Land Registry's information system (ISKN). For the system to function best and interconnect, it has to address corporate requirements and align ISKN architecture for it to conform to the Slovak legislation and meet the criteria of relational area-based database systems. This means that the cadastral map should be able to represent and provide spatial information related to land rights, restrictions and responsibilities not only in 2D for land parcels, but also in 3D for properties, construction, buildings, apartment units, and underground infrastructures. Such a system can be described as a 3D cadaster [3]. 
Traditional two-dimensional (2D) land management records no longer meet the demands of modern society. For instance, Aien et al. [4] believe a 2D plot to be no longer an appropriate fundamental spatial component of the cadastral system for managing and registering three-dimensional (3D) information in large multi-parcel buildings and layered parcels. Resolution of problems in society requires more information than provided from one single data set, and this is equally true for problems with a spatial concept. It is inevitable for these availability problems to be addressed in well-maintained links between spatial data sets and other basic or key data sets, for example, on addresses, persons, companies, buildings and land rights [5,6], a view also shared by [3,7-9].

Construction, investment and ownership in buildings and infrastructure have been considerable in recent years and these have significantly driven the registration of 3D plots [10]. The solution lies in a modern land registry information system with 3D recordkeeping [11]. In [12], authors state that, despite the efforts of much research into 3D cadastral systems, no country in the world has a true 3D cadaster, whose functionality is always limited in some manner $[13,14]$. Available literature provides various examples of extensive research into 3D cadasters and 3D cadastral systems that have been implemented. However, in most countries the legal aspects of 3D real property and its incorporation into 3D cadastral systems have not been so rigorously examined. Authors in $[15,16]$ have given an overview of 3D land registry systems in 15 countries.

A 3D column charter of rights has necessitated the development of a 3D system capable of both visualizing multi-dimensional rights and restrictions and of being spatially sliced, as stated in $[17,18]$.

In some cases, the term $4 \mathrm{D}$ has already appeared. The fourth dimension (time) has already been semantically integrated in many cadastral systems as an attribute (i.e., date of cadastral changes); however, a $4 \mathrm{D}$ graphical representation of the data remains a major challenge [11].

The paper discusses the proposal of new real estate management technology integrated into Slovakia's existing 2D-based Land Registry. Slovakia is a country in Central Europe, which was established in 1993 from Czechoslovakia's split. It has about five million residents. At the turn of the 19th and 20th century, it was a part of the Austro-Hungarian monarchy. During this period, a stable cadaster (cadaster/cadastre of real estates, land registry) was also built and the countries of Central Europe have common bases for its records (Czech Republic, Austria, and Hungary). The Land Registry is administered by the state through a central body, the Office of Geodesy, Cartography and Land Registry of the Slovak Republic (SR). It manages the cadaster management methodology, manages data and the Real Estate Cadaster Information System (ISKN). Disclosure of cadastral data is governed by the Cadastral Act. The cadaster of the Slovak Republic is public and besides selected data (personal identification number-ID) it is possible to see also the personal part of cadastral data (name of the owner and related property) on the cadaster portal. Cadastral data sets for further processing are provided only to selected authorities and institutions under The Land Registry Act. It is for consideration whether the data that is publicly accessible is not very detailed and it would probably be appropriate to set up new rules for the disclosure of personal data kept in cadastral databases.

Structures (buildings) are identified as located on parcels whose property rights and titles are tied strictly to the land. These ties are loose and ambiguous because a single building can be located on several parcels or several buildings can be located on a single parcel. Buildings have no unique Land Registry identification code and are not displayed on parcels in the register's graphics. This traditional concept leads to contradictions between the availability of relevant information and the requirement for entries to provide unambiguous identification of the properties. Even though the law has allowed a building and the land under it to be owned by different entities since 1950, this principle was never really integrated into the Land Registry. In addition, the unique identification system for the different owners of the land, buildings in the plot, and their interiors, to have been used in registration starting in the 1990s and using the land-building-interior hierarchy (either residential or commercial), has yet to be implemented.

The Land Registry Act (Act 162/1995 Coll., as amended) mandates the recording of parcels, buildings and interiors in the Land Registry, so the legislative basis of registration does not have 
to be amended in any way. What needs to be changed is the information system's structure and links, in order to create unique graphical objects of real estate yet to be visualized (buildings and interiors). When they are visualized, the logical implication would be a layered, three-dimensional real estate map.

In SR, the cadastral data structure is represented by digitized ownership sheets, which is considered being outdated and obsolete. The main task is therefore to create structured data and attributes for all types of real estate, i.e., land, buildings and premises in buildings, to define their links and hierarchy, which is absent in the current cadaster except for plots. Cadaster primarily records real estates and rights to them. Registering of buildings (and premises) in the cadaster would create objects defined by the ownership of given building. These objects could then be used for further interoperability with other GISs.

It is a particularly sensitive topic to intervene in the current perception of cadastral data. A fundamental radical change, like an independent representation of buildings as cadastral objects, raises many questions whose framework should be outlined in terms of: information system (design of database model of registered attributes, definition of links and hierarchy with regard to performance and amount of provided information), legislative (definition of rights-limits, boundaries to buildings, their relation to land, questions of soil protection, structures on the surface, below and above it), interoperability of information systems (without the objects representing buildings in the cadaster and registration of rights to them, there can be no connection with other information systems as INSPIRE, regular state population and housing census, etc.). The aim of this paper is to outline the possibility of changes and provide a basis for a much needed discussion on modification of cadastral record keeping. The principles of cadastral records in the SR are approximately 100 years old.

\section{Materials and Methods}

\section{The Current State of Registering Real Estate in Slovakia}

Currently, graphical records in the Land Registry include only parcels and liens. The lands themselves appear in the ' $C$ ' and ' $E$ ' Registry parcels found in the Land Registry.

C-Parcels are the fundamental real estate basic reference covering all administrative cadastral districts with nothing else remaining. The land's geometry, position, unique identifier, and mandatory attributes (area, type of land, use) is registered. It is possible for some C-Parcels to have no title or other ownership.

E-Parcels are a subset of the C-Parcels where, if a C-Parcel has no titles or other ownership, the entire area will constitute a parcel (or multiple parcels or parts thereof) of the E-Parcel, whose boundaries are positionally independent of the C-Parcels and form a patch of land with no title to it. In essence, these E-Parcels are leftover parcels from the pre-socialist land registry. During Communism, all ownership of land was abolished. Parcels seized from their original owners were merged under the management of state agricultural cooperatives were entered in the Land Registry with no further information about previous ownership.

The parcels are viewed separately in the ISKN, each with its own identification code, properties, and matching graphics in the map produced according to ISKN topology rules (Figure 1).

Even though the buildings are the most valuable real estate and their price far exceeds the price of the land on which they are built, the Land Registry fails to take that into account. Buildings are registered according to the principle of medieval feudalism that existed when the Land Registry was established and merely recorded in a descriptive manner as standing on land. It cannot be unambiguously stated whether an entry describes a specific building or shows it on the map. Everyday there are arguments that there is only a small percentage of cases where several buildings are on a single parcel or a single building on several parcels; however, since it is a central state registry, there should be no tolerance as to whether some buildings are neglected as if they did not exist. The Land Registry map section basically does not include these buildings and they exist only in the C-Parcel 
layers partially in planimetric lines. They do not have their own structures entered in the Land Registry, a complete paradox and an anachronism in terms of their significance and features.

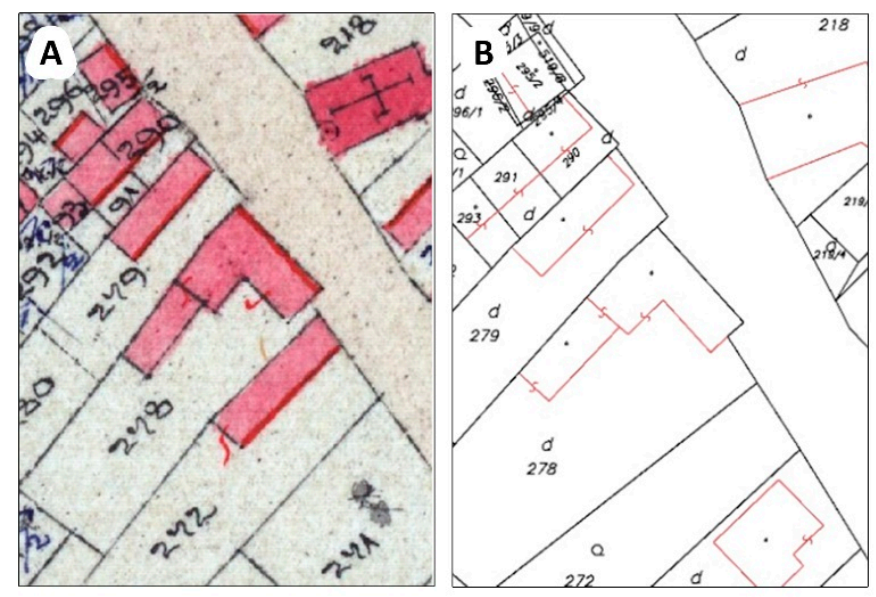

Figure 1. (A) Land Registry Map; (B) Real Estate Registry Map.

Like parcels that have a unique identifier (in this case, the parcel number), buildings should also have a unique identifier in both the Land Registry map section and its descriptive section. Since 1950, the principle of 'superficies solo cedit' has been not applied in Slovakia, meaning that not everything built on land belongs to its owner. If a building is going to be displayed and described, it needs to exist in the ISKN in the similar manner as in the E-Parcels, which are a subset of the C-Parcel area (C-Parcels with no titles). The analogy of the E-Parcel applies both to geodetic (SGI) and descriptive (SPI) information in the Land Registry.

\section{Results and Discussion}

Real estate should be entered in the Land Registry according to the hierarchy and links between whatever is entered therein. Each object or part thereof must be a subset of the C-Parcel(s). A building may include residential and/or other interiors-all residential/office interiors must be a subset of a particular building, and their existence depends on the existence of the building where they are located. Interiors have their own independent property titles that can be different from the building's title. A separate chapter covers the registration of residential/commercial interiors, which may start once the basic issue of building registration has been fully resolved from the facts above.

\subsection{Building a Unique Identification Principle}

Land Registry parcels are separate entries with unique identification codes, properties and matching graphical representation in the map section. These records exist in it so there is no requirement to create them.

The suggestion is to uniquely identify buildings located in Slovakia similarly to the parcel numbering system. The identifier would be incorporated into the descriptive SPI and graphic SGI sections of the Land Registry and clearly designate the building therein. The existing house numbering system is not adequate as an analysis determined that not all buildings are numbered or several buildings may have the same conscription number (houses in Slovakia have two numbers: a conscription and orientation one, e.g., Street 613/22). For these reasons, the conscription number would not be suitable as a unique identifier in the new system for entering structures in the Land Registry.

Considering the current state of the Land Registry in Slovakia and to preserve the principles and links in the existing database systems as well as the expected system requirements, the following principles for 'Building a Unique ID' (JIS) are proposed:

- $\quad$ Easy and clear interpretation of Land Registry documents, excerpts, and maps. 
- Creation of an independent series of natural numbers beginning with 1 and incremented by 1 .

- JIS would be a combination of the Land Registry code and the JIS custom code.

- Land Registry excerpts, legal documents, and map exports would be indicated like parcels, where the JIS custom code would be sufficient because the document would clearly indicate the cadastral district where the structure originates. The combination of KKKKKK-SSSSSS is still possible, where KKKKKK is the cadastral district code and SSSSSS is the JIS custom code, mainly used for structured formulas.

- When real estate is registered in the Land Registry, it would be automatically assigned a JIS code and Land Registry staff would not need to allocate it in advance.

\subsection{ISKN Changes from Land-Building Map Layers}

The new building registration method would require the ISKN to be adapted to the new requirements, and the existing ISKN database would need the following two additions:

- JIS.

- $\quad$ Temporary ID (DIS), to be used in the Advanced Survey (ZPMZ) for the ISKN update. DIS should cover cases where multiple buildings would be assigned the same ZPMZ. The DIS in the ISKN would be a combination of the ZPMZ and a custom number (natural numbers starting from 1 an incrementing by 1 ).

The ISKN real estate graphical section will need to include the entire geometry of the buildings and any and all additional planimetric elements (Figure 2).

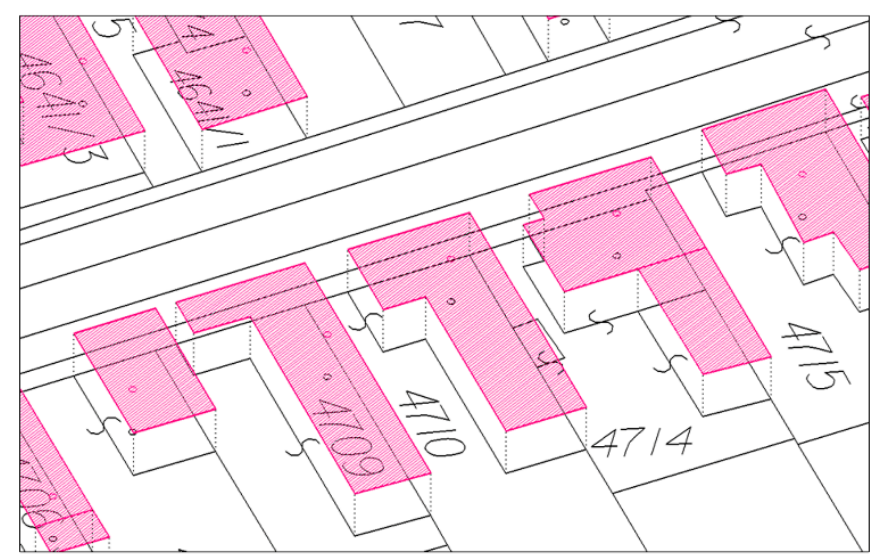

Figure 2. C-Parcel axonometry and structures above the image plane-solution.

The new procedure will bring the following changes to current SGI understanding and the Land Registry geodetic information exchange architecture (VGI), which will continue to be used even if the existing de-centralized ISKN were to be changed to a central land and real estate management system (CSKN):

- There would need to be a definition of the 'STAVBA' (STRUCTURE) layer that would contain the closed planar objects representing the building. All these objects would include a mandatory non-zero DIS attribute, unless it has been registered in the Land Registry, along with the already registered JIS.

- There would also need to be a definition of the 'STAVLIN' layer, which would include the optional additional plane measurement of a specific building. The building identification attributes are the same as for the 'STAVBA' layer. As a rule, each structure can only have a single 'STAVLIN' sub-structure. No 'STAVLIN' can exist independently without the 'STAVBA', so all non-zero JIS and DIS codes used in 'STAVLIN' must be paired with 'STAVBA'. 
The names of the LR geodetic information format files are:

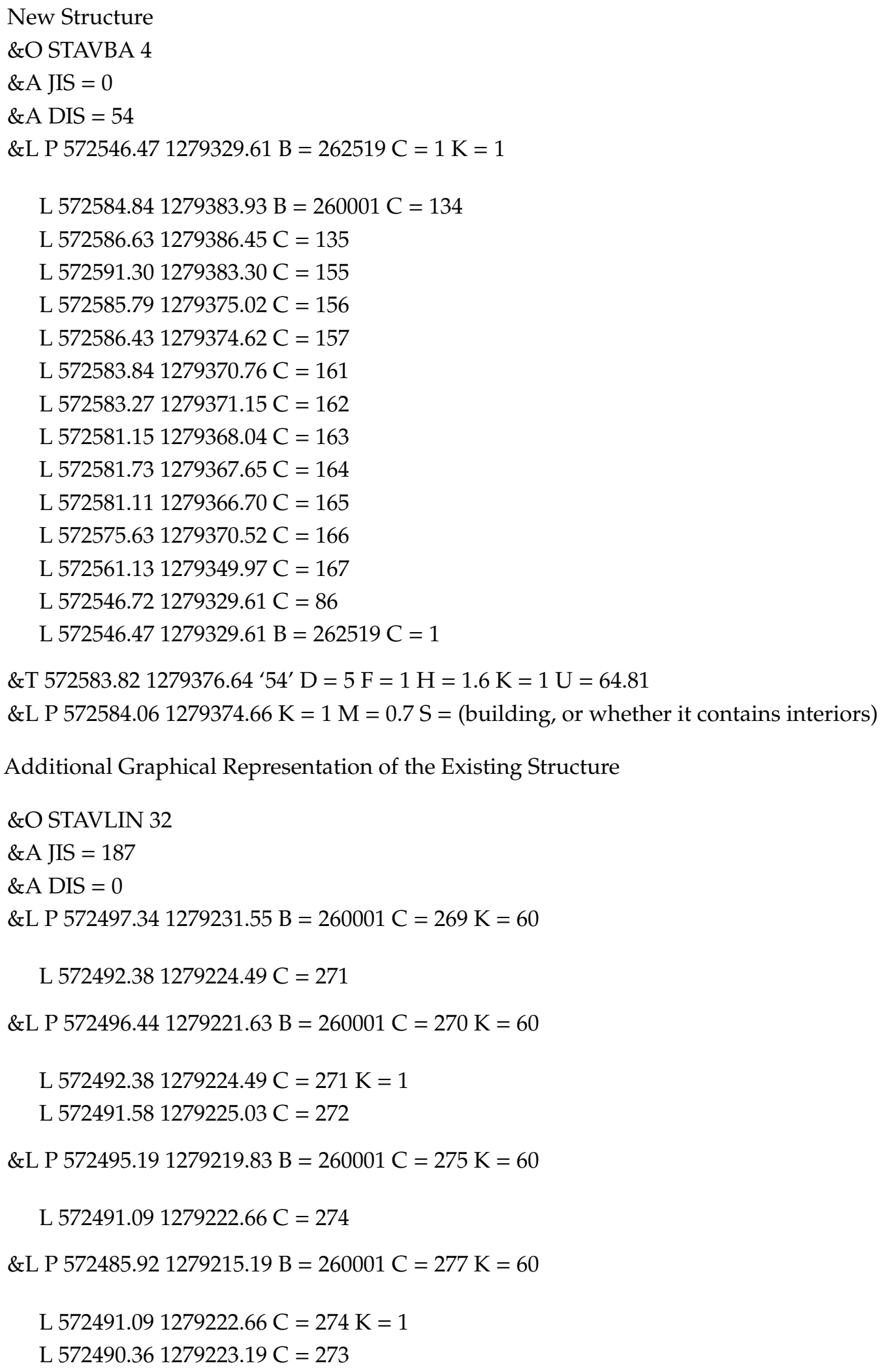

These changes to the model cover the entire building registry and not just new entries. Buildings already registered can be updated and adapted to the system (Figures 3 and 4). 


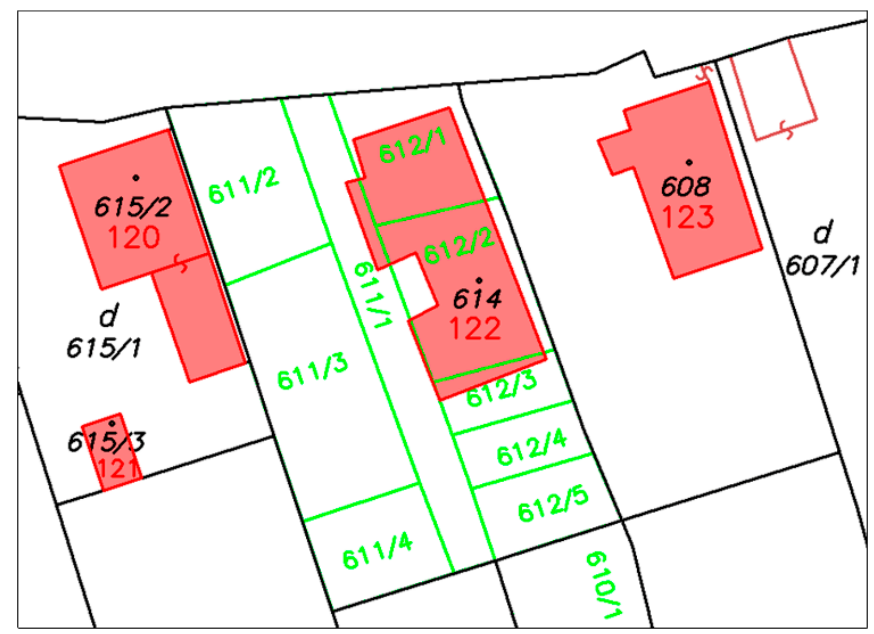

Figure 3. Land Registry Map (C-Parcels), Designated Registry (E-Parcels) and Building Map (Colored Areas) Common Graphical Representation (structures with JIS Code in red).

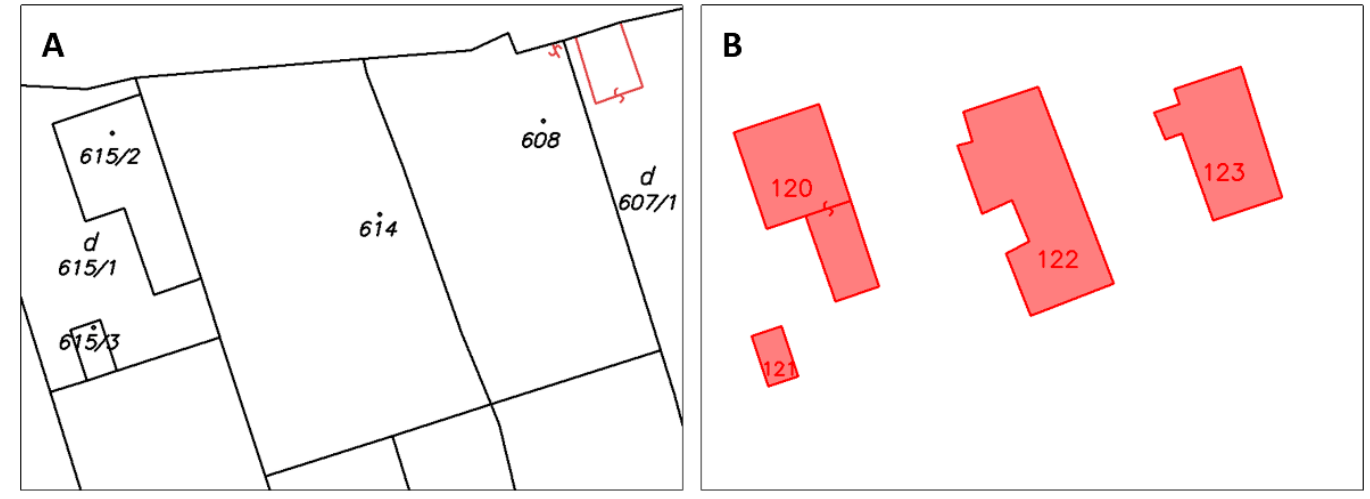

Figure 4. (A) Post-Implementation C-Parcel Registry Map W/ KLADPAR Layer (Planar C-Parcels, Land Types and Parcel Number) and ZAPPAR (Additional Line Drawing to KLADPAR Object Layer) Graphical Representation; (B) STAVBY and STAVLIN Separate Layer Graphical Representation.

\subsection{Measuring Buildings and Concentrating on Changes}

The main focus of the real estate update process lies mainly in the geometric plans and partially in the ZMVM-based tasks and wide ranging tasks such as updating the Land Registry (OKO) and land consolidation (PU). As a rule, every new building requires a geometric plan and must undergo a building approval procedure. This means that almost all new buildings will be entered into the ISKN through the geometric plans registration process. The method will be the same as before, just the form and the content of the records will change, and here it is advisable to consider how to set the survey procedure to concentrate on the structure itself. Section 6 of the Land Registry Act requires the entering into the Land Registry of all buildings firmly joined to the ground through a solid foundation, either by penetration into the ground or through a projection of its outer perimeter onto the ground (buildings with above-ground and/or underground stories, either identified or not identified by a conscription number and under construction where title has been established).

The survey itself is usually conducted ambiguously and diversely by Authorized Surveyors and State Inspectors acting in accordance with Slovak law. However, the legislation is also very ambiguous. Integrating the definition of structure boundaries with the Building Act may not be a good solution. Several points have to be borne in mind:

- The Land Registry provides a record of the legal boundaries of property titles, which may not always match the structural boundaries of the building (neighboring buildings, apartment buildings, twin houses, boundaries running through the middle of a wall). 
- To define a basic structure for the Land Registry purposes, the building's useful area on the floor closest to the ground is essential and is the most suitable link to the C-Parcel where the building is located).

- Structures should serve as the basis for future layers and the graphical representation of any potential future interior on other floors of the building (above or below the ground), which may be of a completely different shape (e.g., River Park-Figure 5).

Because of how the geometric design practices are currently drafted, it would be appropriate to define how the building is going to be measured. The definition could be as follows:

'The basic storied structure is measured as the projection of its perimeter at the ground floor, including any mezzanine or staircase therein. Buildings with underground stories and no upper stories would include the projection of the floor area closest to the ground, including any mezzanine or staircase therein (Basement 1 ).'

It is logical for no definition to cover all building designs and today surveyors have a certain degree of freedom to search for the best solution either with the cooperation of the owner and/or state authority, or through records. This definition basically links a building to the ground and parcel itself (for example, when reclassifying agricultural land for construction or with land type classification). The reference point of a building correlates with the height of its entrance and additionally forms the prerequisites for defining the structure's future layers, which may have different owners and where each new story can be assigned a different purpose (residential/commercial). The other layers can be likely derived easily without direct measurement from the 'STAVBA' basic layer and the completed building.

The advanced solution, including the interior, will be part of future Land Registry changes and must follow a successful implementation of the updated model for registering the structure in the Land Register. Temporarily, any irregular building designs on different floors could be shown in the 'STAVLIN' layer, which could represent the outer maximum projection of the structure outside the roof overlap to give some information about the dimensions of the building's title boundaries closest to the ground together with its maximum dimension (River Park, Figure 5). 'STAVLIN can also be added separately to an existing geometric plan of the structure together with its JIS code. When the structure is registered, it will be either as a new building or as replacing an existing building according to the rule of a single 'STAVLIN'. It is understandable that STAVLIN will not be required for the majority of standard designs.
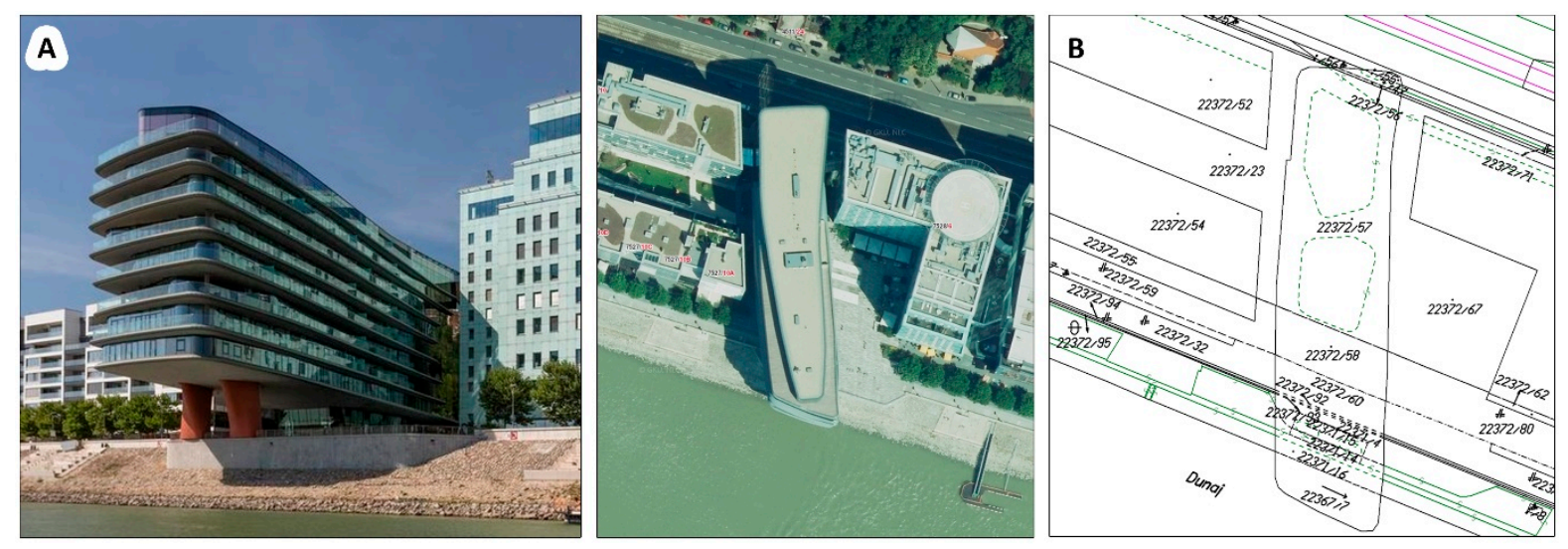

Figure 5. (A) River Park; (B) Land Registry Map Simultaneous Graphical Representation

As far as the produced geometric plan itself is concerned, the only change covers the building and its lines in the VGI exchange format from the 'KLADPAR' layers (containing C-Parcels and parcel numbers) or 'ZAPPAR' layers (containing an additional line drawing to the 'KLADPAR' structural layers) moved to the 'STAVBA' and 'STAVLIN' layers, as described above (Figure 6). The DIS or JIS 
would then be added to the paper graphical representation, and it would be appropriate to highlight the building in a different color in the geometric plan and not just in the ZPMZ. A requirement would be to change the 'STAVBA' tag in the XML file for the SPI registration, which is now assigned illogically. However, the critical procedure is adding the DIS and JIS codes. Paper excerpts will need to include the building's DIS code and the present condition of the building; for a strange reason it is currently stated only in the XML file and the excerpt cannot tell you whether the building has been reconstructed or newly erected. The same building may even be passed to another parcel in the geometric plan. It follows logically that the excerpt should have the buildings balanced in a separate section along with the pre-existing and existing conditions, similar to the parcels.

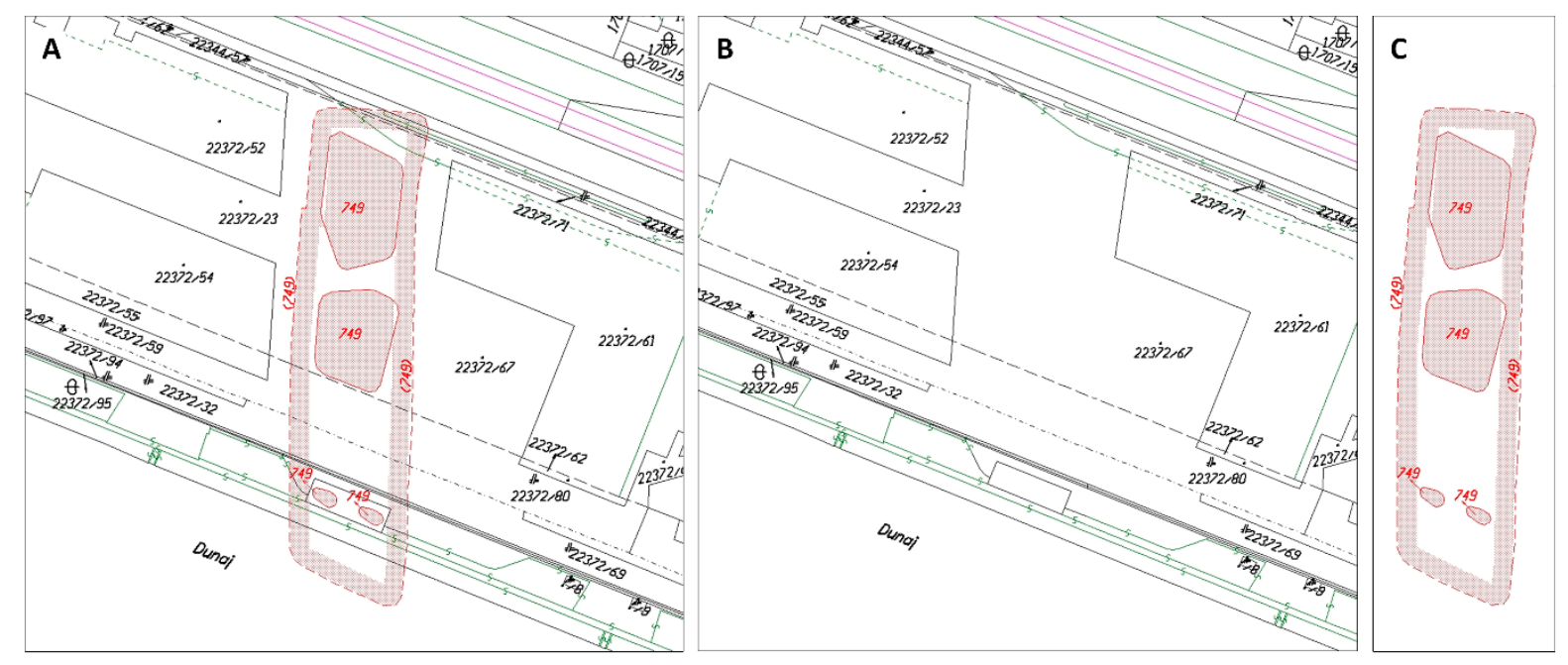

Figure 6. (A) River Park Non-Standard Design: Post-Implementation Full Land Registry Information Representation Option. Some layers are differently colored for easy reference. The figure is illustrative and may neither conform to technical regulations, nor copy the entry in the Land Register. The 'STAVBA' layer is highlighted with a solid red line, the 'STAVLIN' layer with a dashed red line. River Park's JIS code is 749; (B) Areas Adjacent to River Park: Post-Implementation Land Register Information Representation Option W/O STAVBA and STAVLIN Layers; (C) River Park Building: Separate Post-Implementation STAVBA and STAVLIN Layer Representation Option.

The final piece of information advisable to record and illustrate is whether the building contains residential and commercial areas with different owners (code, map designation).

It is essential to be aware of the new 'STAVBA' and 'STAVLIN' layers as an integral part of the Land Registry map and in no case will the building information be lost if the outline is not included in the 'KLADPAR' layer. The map should not be understood only in the context of the SGI software (KOKES) and its integration with the SGI management (SKM) or VGI exchange format. Specific layers of the original 'KLADPAR' layer will contain lines, symbols, parcel numbers, cartographic parcel numbers (abbreviated and shifted) in the new ISKN-SGI. Also the SPI will provide building information in separate tables similar to information about the land involved. Links in the SPI will be provided by the identification code and in the SGI by the position and geometry in terms of their projection.

\subsection{ISKN New and Reconstructed Building Entries}

Buildings will be automatically entered in the ISKN system, based on structured VGI and XML files, if the CSKN system currently under development is implemented. Were an entry to be made in the old system, before the building could be projected in layers and registered in the SPI, there would have had to be an automatic establishment of the JIS code based on the DIS code just prior to entry.

A single application with the following features can do the following: 
1. Checking integrity between VGI and XML files (same number of buildings and same DIS). Unless the documents contain a building, the application will end. Otherwise, it proceeds to the next step.

2. Seeking the lowest available JIS number in the relevant LR area.

3. Creating a copy of the VGI, processes it and replaces each non-zero DIS with a zero JIS incrementally based on availability.

4. Creating a DIS-JIS comparison reference.

5. Adding the JIS code to the XML file according to the comparison reference.

6. Continuing the SPI entry as before, but with the JIS code added to the buildings (then updating the application). Here it would probably be appropriate to enter the DIS code in the form of ZZZZ-DDD, where ZZZZ is the ZPMZ number and DDD the custom DIS code within the ZPMZ. This will provide the link between the building code in the geometric plan and the code in the ISKN.

\section{Conclusions}

The solution presented here is not complicated and brings Land Registry property management to a whole new level, providing a range of benefits for small system structure changes:

- $\quad$ Land Registry building entries would be easily identifiable.

- Graphical representation would be displayed independently of the land itself and layered.

- Buildings with lines intersecting vertically would be shown graphically.

- The ground level and roof level could be used as attributes to model a simplified 3D building image above the map plane.

- The measurements themselves would basically remain unchanged to not burden the geometric design technologically.

- Were layered graphical representation of interiors to be later required, the solution would create a good basis for "3D land registries" and other land registry related tasks.

- A foundation would have been created for linking various building-related information and establish Building Information Management (BIM) for the Land Registry map to become the basic index map for various information systems (Figure 7).

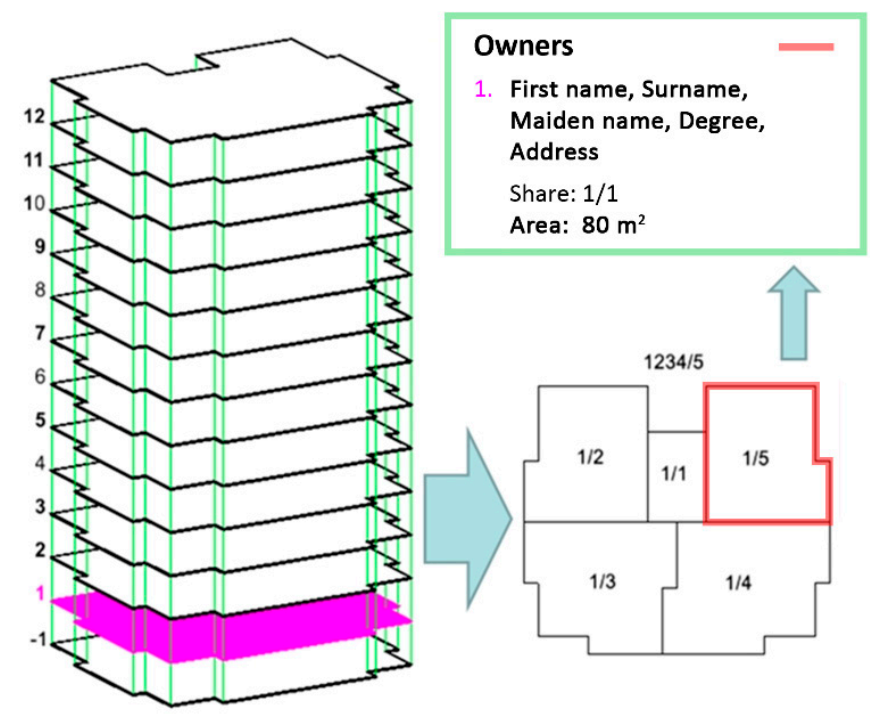

Figure 7. Example of an Interior (Residential/Office) Land Register Information Representation. 
New buildings will need to be registered into the ISKN system as the first step toward ending registration under the old rules. The next step would then be to migrate existing buildings to the new system. While new buildings would be registered in the ISKN mainly by third parties, the existing buildings would be mainly updated by Land Register staff. However, it is possible to campaign toward moving it to the commercial sector.

There would be three basic parts:

- Building information error and integrity analysis between SPI and SGI.

- Error correction.

- Conversion of SPI and SGI into the new model, including automated batch processing control.

Further technologies depend on the approach Ministry representatives take and their enthusiasm to move forward with the issue.

If Land Registry registration is to continue improving, it is high time to create the conditions for consistent registration of buildings, subsequent visualization of their interiors and including other structures covered in the Construction Act (such as roads, surface areas and airports). The value of these non-registered buildings as capital investments is high, and a central registry of titles to these structures has yet to be established. It is a paradox that contradicts social needs and cannot be solved without a systematic land registry solution.

Author Contributions: Conceptualization, V.R.; data curation, Z.M. and F.P.; formal analysis, V.R. and Z.M.; investigation, V.R. and Z.M.; methodology, V.R. and Z.M. software, V.R.; writing-original draft, V.R., Z.M. and F.P.

Funding: This work was conducted within the framework of a research project granted by the agency VEGA of the Slovak Republic, Grant No. 1/0673/16 and by the agency KEGA of the Slovak Republic, Grant No. 008SPU-4/2017 and APVV-17-0377.

Conflicts of Interest: The authors declare no conflicts of interest.

\section{References}

1. FIG. The FIG Statement on the Cadastre; The International Federation of Surveyors (FIG): Copenhagen, Denmark, 1995; ISBN 0-644-4533-1.

2. Hudecová, L.; Geisse, R. Evaluation of the Status of Real Property in Rural Areas. Slovak. J. Civ. Eng. 2018, 26, 50-55. [CrossRef]

3. Kitsakis, D.; Kalantari, M.; Rajabifard, A.; Atazadeh, B.; Dimopoulou, E. Exploring the 3rd Dimension within Public Law Restrictions: A Case Study of Victoria, Australia. Land Use Policy 2019, 85, 195-206. [CrossRef]

4. Aien, A.; Rajabifard, A.; Kalantari, M.; Williamson, I. Review and Assessment of Current Cadastral Data Models for 3D Cadastral Applications. In Advances in 3D Geoinformation. Lecture Notes in Geoinformation and Cartography; Springer International Publishing AG: Cham, Switzerland, 2017; pp. 423-442. [CrossRef]

5. Döner, F. Evaluation of Cadastre Renovation Studies in Turkey. Surv. Rev. 2014, 47, 141-152. [CrossRef]

6. Mika, M. An Analysis of Possibilities for the Establishment of a Multipurpose and Multidimensional Cadastre in Poland. Land Use Policy 2018, 77, 446-453. [CrossRef]

7. Stoter, J.; Salzmann, M. Towards a 3D Cadastre: Where Do Cadastral Needs and Technical Possibilities Meet? Comput. Environ. Urban. Syst. 2003, 27, 395-410. [CrossRef]

8. Paasch, J.M.; Paulsson, J.; Navratil, G.; Vučić, N.; Kitsakis, D.; El-Mekawy, M. Building a Modern Cadastre: Legal Issues in Describing Real Property in 3D. Geod. Vestn. 2016, 60, 256-268. [CrossRef]

9. Ho, S.; Rajabifard, A.; Stoter, J.; Kalantari, M. Legal Barriers to 3D Cadastre Implementation: What Is the Issue? Land Use Policy 2013, 35, 379-387. [CrossRef]

10. Karki, S.; Thompson, R.; Mcdougall, K. Development of Validation Rules to Support Digital Lodgement of 3D Cadastral Plans. Comput. Environ. Urban. Syst. 2013, 40, 34-45. [CrossRef]

11. Kim, S.; Heo, J. Registration of 3D Underground Parcel in Korean Cadastral System. Cities 2019, 89, 105-119. [CrossRef]

12. Drobež, P.; Fras, M.K.; Ferlan, M.; Lisec, A. Transition from 2D to 3D Real Property Cadastre: The Case of the Slovenian Cadastre. Comput. Environ. Urban. Syst. 2017, 62, 125-135. [CrossRef] 
13. 3D Cadastres Home-GDMC. Available online: http://www.gdmc.nl/3DCadastres/ (accessed on 28 March 2019).

14. Marcin, K. Registration of Untypical 3D Objects in Polish Cadastre-Do We Need 3D cadastre? Geod. Cartogr. 2012, 61, 75-89. [CrossRef]

15. Van Oosterom, P. (Ed.) Best Practices 3D Cadastres-Extended Version; International Federation of Surveyors (FIG): Copenhagen, Denmark, 2018.

16. Van Oosterom, P. (Ed.) Best Practices 3D Cadastres; The International Federation of Surveyors (FIG): Copenhagen, Denmark, 2019.

17. Karki, S. 3D Cadastre Implementation Issues in Australia. Master's Thesis, University of Southern Queensland, Toowoomba, QLD, Australia, 2013.

18. Vučić, N.; Roić, M.; Mađer, M.; Vranić, S.; van Oosterom, P. Overview of the Croatian Land Administration System and the Possibilities for Its Upgrade to 3D by Existing Data. ISPRS Int. J. Geo-Inf. 2017, 6, 223. [CrossRef]

(c) (2)

(C) 2019 by the authors. Licensee MDPI, Basel, Switzerland. This article is an open access article distributed under the terms and conditions of the Creative Commons Attribution (CC BY) license (http://creativecommons.org/licenses/by/4.0/). 